\title{
Defensin Susceptibility and Colonization in the Mouse Model of AJ100, a Polymyxin B-Resistant, Brucella abortus RB51 Isolate
}

\author{
Shirley M. Halling • Allen E. Jensen • \\ Steven C. Olsen
}

Received: 9 August 2007 / Accepted: 6 October 2007/Published online: 23 January 2008

(C) The Author(s) 2008

\begin{abstract}
Intracellular pathogens selected for increased susceptibility to polycations are commonly attenuated, yet the effect of decreased susceptibility to polycations on pathogenicity has not been researched. The polymyxin-resistant mutant Brucella abortus AJ100 was characterized by comparing its susceptibility to the polycationic antibiotic polymyxin $\mathrm{B}$, defensins, and lactoferricin, and its colonization and clearance in the mouse model to the parent strain RB51. MIC (minimum inhibitory concentration) values determined by Etest for AJ100 and RB51 were 1.5 and $0.25 \mu \mathrm{g} / \mathrm{ml}$, respectively. Though AJ100 is less susceptible to polymyxin B than RB51, it was more susceptible than its parent strain to the cationic defensins melittin, magainin 2, and cecropin $\mathrm{P} 1$. In the mouse model, initial colonization of the spleen was lower for AJ100 than RB51, and the rate of clearance from the spleen was faster for AJ100 than RB51. However, initial colonization and clearance rates of AJ100 from the liver were indistinguishable from those of RB51. This study suggests that the susceptibility profile of Brucella to polycationic defensins rather than polymyxin B may be indicative of differential survival in the spleen and liver in the mouse and is indicative of spleen and liver residential macrophages' differing ability to inactivate Brucella.
\end{abstract}

\footnotetext{
S. M. Halling $(\bowtie) \cdot$ A. E. Jensen $\cdot$ S. C. Olsen

Bacterial Diseases of Livestock Unit, National Animal Disease Center, Agricultural Research Service, U.S. Department of Agriculture, 2300 Dayton Avenue North, P.O. Box 70, Ames, IA 50010, USA

e-mail: Shirley.Halling@ars.usda.gov
}

\section{Introduction}

Brucella is a facultative intracellular Gram-negative bacterium that causes food animal losses due to reproductive failure and is transmitted to humans primarily through contact with infected animals at parturition and through consumption of contaminated, unpasteurized milk and soft cheeses. Brucella persists in infected animals, surviving in macrophages even though these cells possess an arsenal of compounds including polycationic antimicrobial peptides of innate immune systems designated "defensins" that aid in destroying engulfed bacteria.

The outer membranes (OM) of Gram-negative bacteria are composed chiefly of lipid A containing LPS and are a target of polycationic compounds such as polymyxin B and defensins [4, 6, 15, 22]. Bacteria with a smooth colony are less susceptible to polymyxin B than their mutants that have a rough colony phenotype, which have reduced binding polycations including polymyxin $\mathrm{B}[1,4,16]$. Few studies report the susceptibility of Brucella to polymyxin B as minimum inhibition concentration (MIC) values, but the relative susceptibility of Brucella strains appears consistent across studies [7, 8, 16]. RB51, a rough $B$. abortus vaccine strain, plates with an efficiency of $15 \%$ on medium containing $1.8 \mathrm{U} / \mathrm{ml}$ polymyxin B. A mutant of this strain, RB51/HP [10], herein designated “AJ100," grows in the presence of $1.8 \mathrm{U} / \mathrm{ml}$ of polymyxin B. Comparative MIC values have not been reported for either AJ100 or RB51.

Brucella are relatively less sensitive to polymyxin B and other polycationic compounds than Salmonella; likely both LPS and outer membranes play a role [4, 5, 7, 15, 16, 23]. Mutants of the facultative intracellular pathogens Salmonella and Brucella with increased susceptibility to polymyxin B are attenuated and usually exhibit increased susceptibility to other polycationic compounds as well [1, 
$3,5,9,12]$. The attenuated B. abortus 2308 polymyxin Bsusceptible mutant strain 65.21 (herein designated "SBvrR"), which has a smooth phenotype, is also more susceptible than the parent strain to the defensin mellitin and the polycation poly-L-lysine [19]. How the decreased sensitivities to polymyxin $B$ and mellitin are linked in SBvrR has not been investigated. Further, it is not known if decreased susceptibility to the defensin mellitin alone would attenuate Brucella. Mutants with decreased susceptibility to polymyxin B would be predicted to exhibit decreased susceptibility to other polycations, but this has not been explored.

Mice are used extensively as experimental animals to study the pathogenicity and persistence of Brucella. They persist in the murine immune system, concentrating in the spleen and liver, and are observed in macrophages despite these cells' expressing defensins [9]. Following intraperitoneal injection (i.p.), colonization of the spleen and liver of Brucella is determined by plate counts over several months. High numbers of 2308 , the vaccine challenge strain, are maintained in the spleens of BALB/c mice at 100 days [21], while RB51 is eliminated from BALB/c mice between 4 and 8 weeks [20]. Subcutaneous injection of the smooth polymyxin B-sensitive B. abortus 2308 mutant SBvrR was found to be severely attenuated in the mouse model, scarcely replicating, if at all, in mice. Brucella were cleared from $50 \%$ of the mice by 35 days when given RB51 and by 175 days when given the parent strain 2308 [19].

Here we determine the MIC value for the mutant AJ100 relative to other strains which exhibit susceptibility to polymyxin $\mathrm{B}$, profile the susceptibility of AJ100 to polycationic compounds, and explore the correlation between phenotype regarding susceptibility to polycationic compounds and virulence in the mouse model relative to the parent strain RB51.

\section{Materials and Methods}

\section{Brucella Strains}

Brucella abortus RB51 (RB51) vaccine strain [18], B. abortus RB51/HP (AJ100) [10], B. abortus 65.21(SBvrR) [19], and B. abortus 2308 (2308), a common B. abortus challenge strain, used in this study were obtained from the National Animal Disease Center (ARS/USDA, Ames, IA) culture collection.

Sensitivity to Polycationic Compounds

In vitro activity of polymyxin $B$ was determined by the Etest (AB Biodisk, Piscataway, NJ) containing a preformed gradient covering a continuous MIC range $(0.064-1024 \mu \mathrm{g} /$ $\mathrm{ml}$ ) corresponding to 15 twofold dilutions of polymyxin $\mathrm{B}$ with a precision of 0.5 dilution. Brucella were suspended in saline and the turbidity was adjusted to a $0.5 \mathrm{McF}$ arland standard $\left(5 \times 10^{8}\right.$ colony-forming units $\left.[\mathrm{CFU}] / \mathrm{ml}\right)$. The suspension was spread onto Mueller Hinton (MH; Difco Laboratories, Detroit, MI) or $\mathrm{pH}$-adjusted $\mathrm{MH}$ agar plates using a cotton swab, and the Etest strips applied. Medium $\mathrm{pH}$ values were adjusted prior to autoclaving. Plates were incubated $\left(37^{\circ}\right)$ in ambient air or in an atmosphere of $7.5 \%$ $\mathrm{CO}_{2}$. Results were read after $48 \mathrm{~h}$.

Aqueous solutions of defensins were dropped (1, 2, and $4 \mu \mathrm{l}$ ) onto cultures swabbed as described above to assay strain susceptibility. Stock solutions of the polycationic compounds were prepared as follows: melittin, honeybee venom $(10 \mu \mathrm{g} / \mu \mathrm{l}$; Sigma Chemical Company, St. Louis, MO), magainin 2, frog skin $(1 \mu \mathrm{g} / \mu \mathrm{l}$; American Peptide Company [APC], Sunnyvale, CA); lactoferricin, bovine (1 $\mu \mathrm{g} / \mu \mathrm{l}$; APC); bactenecin, bovine ( $2 \mu \mathrm{g} / \mu \mathrm{l}$; APC); and cecropin P1, porcine $(1 \mu \mathrm{g} / \mu \mathrm{l}$; APC). Plates were incubated at $37^{\circ} \mathrm{C}$ and results were recorded after $48 \mathrm{~h}$. A strain showing no inhibition of growth was recorded as resistant (R). If a zone of no growth was noted, the strain was designated susceptible (S). If a zone of nonconfluent growth was noted at the drop point, the strain was designated intermediate (I).

\section{Animal Inoculation}

Female 10-week-old BALB/c AnNHsD mice (Harlan Sprague Dawley, Indianapolis, IN) were used. Mice $(n=25 /$ treatment [trt]) were inoculated intraperitoneally with $0.2 \mathrm{ml}$ of saline or $0.2 \mathrm{ml}$ of saline containing $1 \times 10^{7} \mathrm{CFU}$ of B. abortus strain AJ100 or strain RB51. Five mice each from the saline control, AJ100, and RB51 groups were euthanized with $\mathrm{CO}_{2} / \mathrm{O}_{2}$ at $1,2,3,4$, and 8 weeks postinoculation (PI). Spleens and livers were weighed and processed for determination of Brucella CFU.

\section{Culture Examination of Spleen and Livers}

Spleens and livers were homogenized in tissue grinders, serially diluted in saline, and plated on tryptose agar (Difco) containing 5\% bovine serum (TSA). After incubation of plates at $37^{\circ} \mathrm{C}$ with $7.5 \% \mathrm{CO}_{2}$ for $72 \mathrm{~h}$, numbers of CFU were determined for each dilution by standard plate counts. Colonies were confirmed as Brucella based on colony morphology, growth characteristics [2], and a Brucella-specific polymerase chain reaction (PCR) procedure as described, previously [13]. 
Statistical Analysis

For statistical comparisons, colonizations of spleen and liver (CFU/g and total CFU/tissue) were analyzed as the logarithm of their value. Due to conversion to logarithm, any colonization data with a value of 0 were analyzed with a value of 1 . Statistical differences between treatments were determined by a general linear models procedure, and significant differences were reported when $p<0.05$. Means for each treatment were compared by use of a least significant difference procedure and are reported as least square mean $\pm \mathrm{SE}$.

\section{Results}

\section{Susceptibility to Polymyxin B}

Etest MIC values of B. abortus strains AJ100 and RB51 differed by sixfold in the presence of $7.5 \% \mathrm{CO}_{2}$. $\mathrm{MIC}$ values were 1.5 and $0.25 \mu \mathrm{g} / \mathrm{ml}$, respectively (Fig. 1). In general as the $\mathrm{pH}$ became more acidic, the Brucella strains were less susceptible to polymyxin B. However, RB51 was less susceptible at $\mathrm{pH} 5$ than at $\mathrm{pH}$ 6. AJ100 did not grow at $\mathrm{pH} 5$.

\section{Susceptibility to Defensins}

Brucella strains were examined for susceptibility to defensins in a drop assay (Table 1). The parent strain of RB51, 2308, was not susceptible to any of the defensins at the concentrations applied. RB51 was susceptible or partially susceptible to two of the defensins, mellitin and cecropin $\mathrm{P} 1$, respectively, but only in the presence of $\mathrm{CO}_{2}$. Among the Brucella strains studied, the pattern of susceptibility to the defensins was most similar between

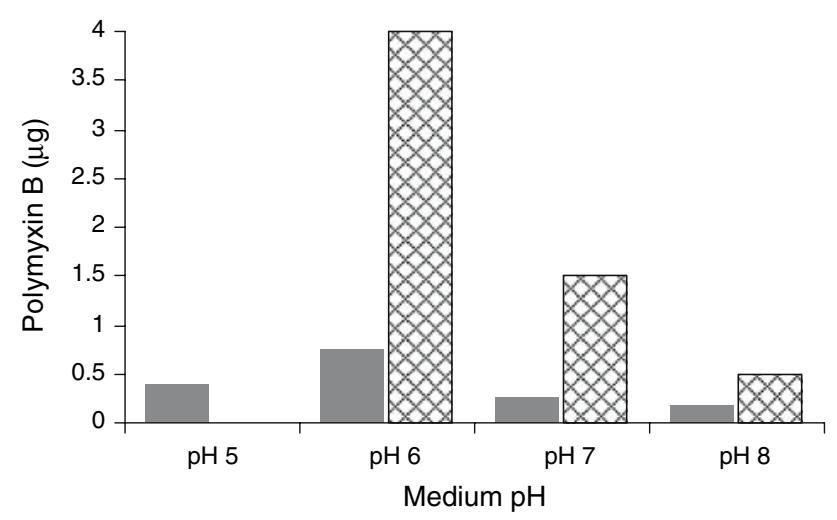

Fig. 1 MIC values of B. abortus strains AJ100 (cross-hatch) and RB51 parent strain (black) for polymyxin $\mathrm{B}$ at $\mathrm{pH}$ values from $\mathrm{pH} 5$ to $\mathrm{pH}$ 8.0. Cultures were grown in the presence of $\mathrm{CO}_{2}$
Table 1 Susceptibility ${ }^{\mathrm{a}}$ of Brucella abortus strains to defensins

\begin{tabular}{|c|c|c|c|c|c|c|c|}
\hline \multirow[t]{2}{*}{ Brucella strain $^{\mathrm{b}}$} & \multicolumn{2}{|c|}{ Melittin } & \multicolumn{2}{|c|}{ Magainin 2} & \multicolumn{3}{|c|}{ Cecropin P1 } \\
\hline & $10 \mu \mathrm{g}$ & $40 \mu \mathrm{g}$ & $1 \mu \mathrm{g}$ & $4 \mu \mathrm{g}$ & $1 \mu \mathrm{g}$ & $2 \mu \mathrm{g}$ & $4 \mu \mathrm{g}$ \\
\hline RB51 A & $\mathrm{R}$ & $\mathrm{R}$ & $\mathrm{R}$ & $\mathrm{R}$ & $\mathrm{R}$ & $\mathrm{R}$ & $\mathrm{R}$ \\
\hline RB51 C & $\mathrm{S}$ & S & $\mathrm{R}$ & $\mathrm{R}$ & $\mathrm{R}$ & $\mathrm{R}$ & I \\
\hline AJ100 A & S & S & $\mathrm{S}$ & $\mathrm{S}$ & S & $\mathrm{S}$ & S \\
\hline $\mathrm{AJ} 100 \mathrm{C}$ & $S$ & $S$ & $\mathrm{R}$ & $\mathrm{R}$ & $S$ & $S$ & S \\
\hline $2308 \mathrm{~A}$ & $\mathrm{R}$ & $\mathrm{R}$ & $\mathrm{R}$ & $\mathrm{R}$ & $\mathrm{R}$ & $\mathrm{R}$ & $\mathrm{R}$ \\
\hline $2308 \mathrm{C}$ & $\mathrm{R}$ & $\mathrm{R}$ & $\mathrm{R}$ & $\mathrm{R}$ & $\mathrm{R}$ & $\mathrm{R}$ & $\mathrm{R}$ \\
\hline SBvrR A & $\mathrm{S}$ & $\mathrm{S}$ & $\mathrm{R}$ & $\mathrm{R}$ & $\mathrm{S}$ & $\mathrm{S}$ & $\mathrm{S}$ \\
\hline SBvrR C & $\mathrm{S}$ & $\mathrm{S}$ & $\mathrm{R}$ & $\mathrm{R}$ & $\mathrm{S}$ & $\mathrm{S}$ & $\mathrm{S}$ \\
\hline
\end{tabular}

${ }^{a} \mathrm{R}$, resistant; $\mathrm{S}$, susceptible; $\mathrm{I}$, intermediate

b $\mathrm{A}$ - grown in ambient air; $\mathrm{C}$ - grown in the presence of added $\mathrm{CO}_{2}$

AJ100 and SBvrR. Both AJ100 and SBvrR were shown to be more susceptible to the defensins mellitin and cecropin P1than their parent strains, RB51 and 2308, respectively. AJ100 was also sensitive to magainin 2, but only in ambient air. None of the strains used in this study were susceptible to either bactenecin or lactoferricin at 8 and $4 \mu \mathrm{g}$, respectively (data not shown).

Tissue Persistence in a Mouse Model

RB51-infected mice had greater $(p<0.05)$ splenic colonization (CFU/g and total CFU) at 1, 2, 3, and 4 weeks PI than AJ100-inoculated mice (Fig. 2). Liver colonization did not differ $(p>0.05)$ between mice given RB51 versus AJ100. Both RB51 and AJ100 were recovered from spleens and livers of injected mice at 4 weeks but not at 8 weeks.

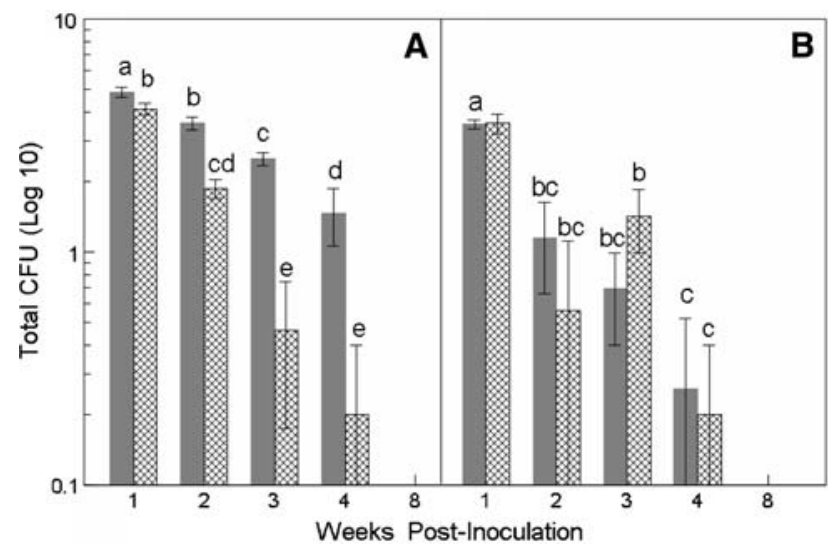

Fig. 2 Colonization of splenic (A) and hepatic (B) tissues (mean $\log _{10}$ total CFU per tissue \pm SE) after intraperitoneal inoculation $(n=25$ mice/treatment [trt] $)$ with $1 \times 10^{7} \mathrm{CFU}$ of $B$. abortus strains RB51 (black columns) or AJ100 (cross-hatched columns). Means with different superscripts differ significantly $(p \leq 0.05)$ for that tissue 
Table 2 Spleen and liver weights postinoculation (PI)

\begin{tabular}{lccccrrr}
\hline Weeks PI & \multicolumn{3}{c}{ Spleen weight $(\mathrm{mg})$} & & \multicolumn{2}{c}{ Liver weight (mg) } \\
\cline { 2 - 4 } & RB51 & AJ100 & Control & & RB51 & AJ100 \\
\hline 1 & $166 \pm 38^{\mathrm{a}}$ & $168 \pm 8^{\mathrm{a}}$ & $82 \pm 7^{\mathrm{b}}$ & & $1062 \pm 105^{\mathrm{a}}$ & $1142 \pm 123^{\mathrm{a}}$ & $856 \pm 61^{\mathrm{b}}$ \\
2 & $162 \pm 29^{\mathrm{a}}$ & $124 \pm 4^{\mathrm{b}}$ & $87 \pm 5^{\mathrm{c}}$ & & $920 \pm 72^{\mathrm{ab}}$ & $938 \pm 98^{\mathrm{a}}$ & $838 \pm 78^{\mathrm{b}}$ \\
3 & $121 \pm 17^{\mathrm{a}}$ & $100 \pm 12^{\mathrm{b}}$ & $81 \pm 10^{\mathrm{c}}$ & & $1085 \pm 65^{\mathrm{a}}$ & $1083 \pm 35^{\mathrm{a}}$ & $985 \pm 32^{\mathrm{b}}$ \\
4 & $125 \pm 16^{\mathrm{a}}$ & $112 \pm 10^{\mathrm{ab}}$ & $99 \pm 2^{\mathrm{b}}$ & & $1024 \pm 88^{\mathrm{a}}$ & $1006 \pm 58^{\mathrm{a}}$ & $1010 \pm 45^{\mathrm{a}}$ \\
\hline
\end{tabular}

Note. Weights are recorded as the mean \pm SE. Means with different superscripts differ significantly $(p \leq 0.05)$ among treatments for that tissue per sampling time

Spleen and liver weights from inoculated and control mice were determined (Table 2). Compared to control mice, spleen weights were greater in mice inoculated with RB51 or AJ100 at 1, 2, 3, and 4 weeks, but not at 8 weeks PI. Compared to AJ100-inoculated mice, RB51-inoculated mice had greater $(p<0.05)$ spleen weights only at 2 and 3 weeks PI. In contrast, liver weights of both RB51 and AJ100 were greater than that of control mice only at week 1 PI. Liver weights between AJ100- and RB51-inoculated mice were significantly different $(p>0.05)$ only at week 2 PI. No statistical difference in weights of spleens or livers among any of the treatment groups was detected at 8 weeks PI.

\section{Discussion}

The Etest was used to determine relative MIC values of Brucella strains for polymyxin B. It is easily conducted and gave relative results similar to those reported using more time-consuming and complex protocols, such as viability tests with time or dilution end points. Though both 2308 and SBvrR are smooth and less susceptible to polymyxin B than RB51 and AJ100, we found similar-fold differences in polymyxin B susceptibility between the mutants and their parents. The MIC value for SBvrR (16 IU/ml) is eightfold lower than that for the parent strain $2308(128 \mathrm{IU} / \mathrm{ml})$ in a microtiter plate format growth assay [19], and, by the Etest, the MIC values were fourfold lower, with values of 6 and $24 \mu \mathrm{g} / \mathrm{ml}$, respectively [11]. The differences observed are likely due not only to protocol differences but also to the higher precision of the Etest. This assay has a precision of 0.5 dilutions, as opposed to twofold dilutions for many other commonly used protocols.

Growth of Brucella slightly increases the $\mathrm{pH}$ of many bacterial culture media though absorption of $\mathrm{CO}_{2}$ acidifies it. As the medium acidifies, there is a concurrent reduction in antimicrobial activity of cations due to a reduction in its charge. However, in the case of $\mathrm{AJ} 100$ susceptibility to maganin was less when cultured in the presence of $\mathrm{CO}_{2}$ than in ambient air. Screening of mutants for change in polycationic susceptibility will need to be carried out in the presence of $\mathrm{CO}_{2}$ even if the strains studied are $\mathrm{CO}_{2}$ independent or a class of mutants is likely to be missed.

The target or locus resulting in increased sensitivity to mellitin either does not cause susceptibility to polymyxin B or has the opposite effect. Characterization of the Brucella BvrR/BvrS mutants has begun and the effect of several loci and likely mechanisms are emerging $[14,15]$. As BvrR/ BvrS compose a two-component system which enables bacteria to quickly and specifically respond to environmental changes by globally modulating and coordinating expression of many gene products affecting different functional pathways, many loci may be involved, especially given that BvrR/BvrS may regulate other twocomponent systems. Identification of loci involved in the disparate susceptibility of AJ100 to the polycationic compounds polymyxin $B$ and mellitin via microarray and other studies could identify specific loci for further study.

Attenuated intracellular bacterial pathogens have been identified by screening for increased susceptibility to polymyxin B. This predicts that increased resistance to polycations would increase pathogenicity. However, this was not found to be the case for AJ100. The observed discordance between susceptibility of AJ100 to polymyxin $B$ and mellitin that we observed relative to SBvrR was resolved by determination of the relative pathogenicity of AJ100 to colonize and persist in a murine model compared to the parent strain. Increased susceptibility of AJ100 to the defensins mellitin, maganin, and cecropin correlated directly with attenuation in the spleen.

Attenuation of AJ100 relative to RB51 was observed in the spleen (Fig. 2) but not the liver. This attenuation may be dependent on differences in polycationic content between spleen and liver resident macrophages, as it has been shown that defensin expression by the innate immune system affects tissue colonization. Transgenic mice expressing a human intestinal defensin were protected from infection by Salmonella typhimurium [17], which otherwise is quite deadly to mice. As the defensins used in this study were isolated from higher organisms, unlike polymyxin $\mathrm{B}$, which comes from bacteria, the profiles of 
sensitivity to defensins may be a better predictor of attenuation for intracellular bacteria than susceptibility to polymyxin B.

In summary, AJ100 is sixfold more resistant to polymyxin B than the parental RB51 strain as determined by the Etest. Though AJ100 was less susceptible to this polycationic antibiotic than its parent strain, it was more susceptible to the cationic defensins, mellitin, maganin, and cecropin. This profile correlated with attenuation of AJ100 in the mouse model. AJ100 did not colonize mice spleens to the same extent as RB51 and was cleared from the spleen faster. On the other hand, livers were colonized and cleared similarly by these two strains. The profile of susceptibility to defensins may predict attenuation better than susceptibility to polymyxin B.

Acknowledgments No endorsements are herein implied. Brand names are necessary to report factually on available data; however, the USDA neither guarantees nor warrants the standards of the products, and the use of the names by USDA implies no approval of the products to the exclusion of others that may also be suitable. The authors thank Deb Buffington, Aileen Hudspith, Darl Pringle, John Kent, and Todd Holtz for technical assistance.

Open Access This article is distributed under the terms of the Creative Commons Attribution Noncommercial License which permits any noncommercial use, distribution, and reproduction in any medium, provided the original author(s) and source are credited.

\section{References}

1. Allen CA, Adams LG, Ficht TA (1998) Transposon-derived Brucella abortus rough mutants are attenuated and exhibit reduced intracellular survival. Infect Immun 66:1008-1016

2. Alton GG, Jones LM, Angus RD, Verger JM (1988) Techniques for the Brucellosis laboratory. Institut National de la Recherche Agronomique, Paris

3. Bader MW, Navarre WW, Shiau W, Nikaido H, Frye JG, McClelland M, Fang FC, Miller SI (2003) Regulation of Salmonella typhimurium virulence gene expression by cationic antimicrobial peptides. Mol Microbiol 50:219-230

4. Freer E, Moreno E, Moriyon I, Pizarro-Cerda J, Weintraub A, Gorvel JP (1996) Brucella-Salmonella lipopolysaccharide chimeras are less permeable to hydrophobic probes and more sensitive to cationic peptides and EDTA than are their native Brucella sp. counterparts. J Bacteriol 178:5867-5876

5. Groisman EA, Parra-Lopez C, Salcedo M, Lipps CJ, Heffron F (1992) Resistance to host antimicrobial peptides is necessary for Salmonella virulence. Proc Natl Acad Sci USA 89:11939-11943

6. Guo L, Lim KB, Poduje CM, et al. (1998) Lipid A acylation and bacterial resistance against vertebrate antimicrobial peptides. Cell 95:189-198

7. Guzman-Verri C, Manaterola L, Sola-Landa A, Parra A, Cloeckaert A, Garin J, Gorvel JP, Moriyon I, Moreno E, Lopez-Goni I
(2002) The two-component system BvrR/BvrS essential for Brucella abortus virulence regulates the expression of outer membrane proteins with counterparts in members of the Rhizobiaceae. Proc Natl Acad Sci USA 99:12375-12380

8. Halling SM (1996) The effects of magainin 2, cecropin, mastoparan and mellitin on Brucella abortus. Vet Microbiol 51:187-192

9. Hancock REW, Scott MG (2000) The role of antimicrobial peptides in animal defenses. Proc Natl Acad Sci USA 97:88568861

10. Jensen AE, Ewalt DR, Cheville NF, Thoen CO, Payeur JB (1996) Determination of stability of Brucella abortus RB51 by use of genomic fingerprint, oxidative metabolism, and colonial morphology and differentiation of strain RB51 from B. abortus isolates from bison and elk. J Clin Microbiol 34:628-633

11. Jensen AE, Halling SM (2007) Effect of polymyxin B and environmental conditions on isolation of Brucella species and the vaccine strain RB51. Comp Immunol Microbiol Infect Dis (Submitted)

12. Lapaque N, Moriyon I, Moreno E, Gorvel J-P (2005) Brucella lipopolysaccharide acts as a virulence factor. Curr Opin Microbiol 8:60-66

13. Lee I-K, Olsen SC, Bolin CA (2001) Effects of exogenous recombinant interleukin-12 on immune responses and protection against Brucella abortus in a murine model. Can J Vet Res 65:223-228

14. Manterola L, Guzmán-Verri C, Chaves-Olarte E, Barquero-Clave E, de Minguel MJ, Moriyón I, Grilló MJ, López-Goni I, Moreno E (2007) BvrR/BvrS-controlled outer membrane proteins Omp3a and Omp3b are not essential for Brucella abortus virulence. Infect Immun 75:4867-4874

15. Manterola L, Moriyon I, Moreno E, Sola-Landa A, Weiss DS, Koch MHJ, Howe J, Brandenburg K, Lopez-Goni I (2005) The lipopolysaccharide of Brucella abortus BvrS/BvrR mutants contains lipid A modifications and has higher affinity for bactericidal cationic peptides. J Bacteriol 187:5631-5639

16. Martinez de Tejada G, Pizarro-Cerda J, Moreno E, Moriyon I (1995) The outer membranes of Brucella spp. are resistant to bactericidal cationic peptides. Infect Immun 63:3054-3061

17. Salzman NH, Ghosh D, Huttner KM, Paterson Y, Bevins CL (2003) Protection against enteric salmonellosis in transgenic mice expressing a human intestinal defensin. Nature 422:522-526

18. Schurig GG, Roop II RM, Bagchi T, Boyle S, Buhrman D, Sriranganathan N (1991) Biological properties of RB51; a stable rough strain of Brucella abortus. Vet Microbiol 28:171-188

19. Sola-Landa A, Pizarro-Cerda J, Grillo M-J, Moreno E, Moriyon I, Blasco J-M, Gorvel J-P, Lopez-Goni I (1998) A two-component regulatory system playing a critical role in plant pathogens and endosymbionts is present in Brucella abortus and controls cell invasion and virulence. Mol Microbiol 29:125-138

20. Stevens MG, Olsen SC, Pugh GW Jr, Brees D (1995) Comparison of immune responses and resistance to brucellosis in mice vaccinated with Brucella abortus 19 or RB51. Infect Immun 63:264270

21. Tatum FM, Morfitt DC, Halling SM (1993) Construction of a Brucella abortus RecA mutant and its survival in mice. Microb Path 14:177-185

22. Vaara J (1992) Agents that increase the permeability of the outer membrane. Microbiol Rev 56:395-411

23. Zhou Z, Ribeiro AA, Lin S, Cotter RJ, Miller SI, Raetz CRH (2001) Lipid A modifications in polymyxin-resistant Salmonella typhimurium. J Biol Chem 276:43111-43121 